\title{
Safety and Efficacy of the Oral Direct Factor Xa Inhibitor Apixaban in Japanese Patients With Non-Valvular Atrial Fibrillation - The ARISTOTLE-J Study -
}

\author{
Satoshi Ogawa, MD; Yukito Shinohara, MD; Kazuhiro Kanmuri
}

\begin{abstract}
Background: Guidelines recommend warfarin as the standard of care for patients with atrial fibrillation (AF) at moderate or high risk for stroke. This phase II study assessed the effects of 2 doses of the factor Xa inhibitor apixaban vs. warfarin in Japanese patients with non-valvular AF. The composite primary endpoint was major and clinically relevant non-major (CRNM) bleeding.

Methods and Results: Two hundred and twenty-two patients with AF and 1 or more additional risk factors for stroke were randomized (1:1:1) to double-blind apixaban 2.5 or $5 \mathrm{mg}$ b.i.d. or open-label warfarin (target international normalized ratio $2.0-3.0 ; 2.0-2.6$ if age $\geq 70$ years) for 12 weeks. The primary endpoint occurred in 1 patient $(1.4 \%)$ in each apixaban group and $4(5.3 \%)$ warfarin patients. There were no strokes, systemic emboli, myocardial infarctions, or deaths in either apixaban group. The warfarin group had 2 ischemic strokes and 1 subarachnoid hemorrhage, but there were no deaths. Major and CRNM bleeds each occurred with higher frequency in the warfarin group vs. either apixaban group. Most adverse events were mild or moderate. No patients had hepatic aminotransferase elevations greater than 3 times the upper limit of normal.
\end{abstract}

Conclusions: In Japanese patients with AF, apixaban 2.5 and $5 \mathrm{mg}$ b.i.d. were well tolerated over 12 weeks. A global phase III trial, which includes Japanese patients, is ongoing (ClinicalTrials.gov Identifier NCT00787150). (Circ J 2011; 75: 1852-1859)

Key Words: Apixaban; Japanese patients; Non-valvular atrial fibrillation; Oral anticoagulant

$\mathbf{N}$ on-valvular atrial fibrillation (AF) is a common arrhythmia in Europe, North America, and Japan. AF affects approximately $1 \%$ of the general population in Western countries and $0.6 \%$ in Japan, with the prevalence increasing significantly with age over 60 years. ${ }^{1,2}$ The risk for stroke is 3- to 5-fold higher in people who have AF than in those without AF in Western and Japanese populations, 3,4 and increases from $1.5 \%$ in $\mathrm{AF}$ patients at age $50-59$ to $23.5 \%$ among those aged $\geq 80$ years. $^{4}$

\section{Editorial $p 1819$}

Although vitamin $\mathrm{K}$ antagonists such as warfarin reduce the stroke risk in AF by as much as $60 \%, 5$ and guidelines recommend them for reduction of stroke risk in AF patients at moderate to high risk of stroke, ${ }^{6-10}$ they are contraindicated in many patients and often underutilized even in eligible patients for whom they are indicated. ${ }^{11-13}$ Warfarin has numerous food and drug interactions, a relatively narrow therapeutic window, increased risk of bleeding, and the requirement for frequent monitoring and dose adjustments. Acetylsalicylic acid (ASA) has been recommended for AF patients at lower risk of stroke, but is less effective than warfarin. ${ }^{6,7}$ In fact, the Japan AF Stroke trial found ASA to be neither effective nor safe; hence, it is not recommended in Japanese guidelines. ${ }^{10,14}$

In the search for efficacious, safe, well tolerated, and convenient alternatives to current anticoagulants for stroke

Received November 29, 2010; revised manuscript received March 9, 2011; accepted March 29, 2011; released online June 14, 2011 Time for primary review: 13 days

International University of Health and Welfare, Mita Hospital, Tokyo (S.O.); Federation of National Public Service Personnel Mutual Aid Associations, Tachikawa Hospital, Tokyo (Y.S.); and Cardiovascular and Metabolism Therapeutics, Pfizer Japan Inc, Tokyo (K.K.), Japan

ARISTOTLE-J Study Group members listed in the Appendix.

Funding: This study was funded by Pfizer Inc and Bristol-Myers Squibb.

Mailing address: Satoshi Ogawa, MD, International University of Health and Welfare, Mita Hospital, 1-4-3 Mita, Minato-ku, Tokyo 108-8329, Japan. E-mail: sogawa@iuhw.ac.jp

ISSN-1346-9843 doi:10.1253/circj.CJ-10-1183

All rights are reserved to the Japanese Circulation Society. For permissions, please e-mail: cj@j-circ.or.jp 


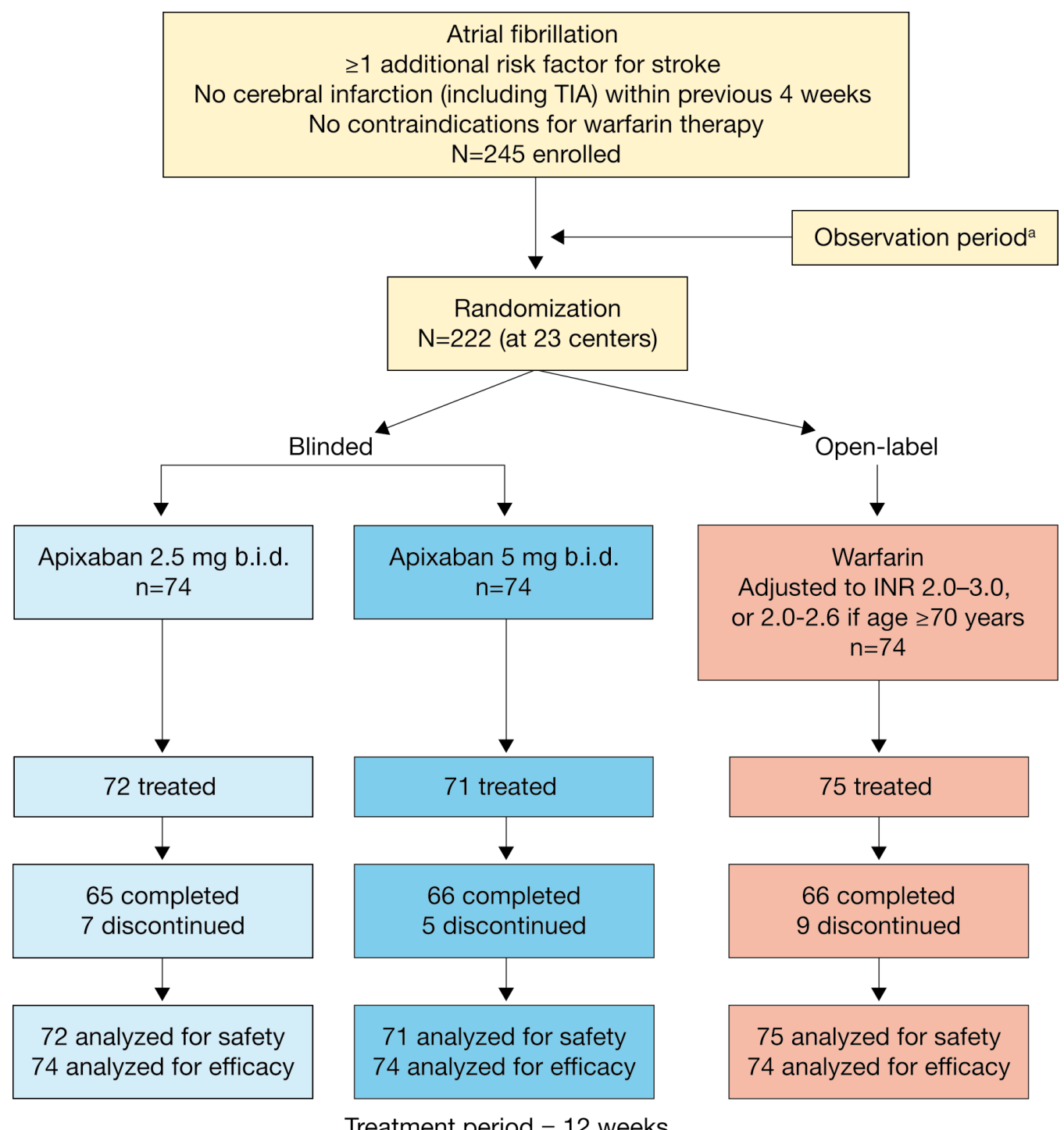

Figure 1. Study design and patient disposition. Of the 74 patients randomized to each group, 1 from the apixaban $2.5 \mathrm{mg}$ b.i.d. group, 2 from the apixaban $5 \mathrm{mg}$ b.i.d. group, and 1 from the warfarin group did not receive study medication. One patient randomized to each of the apixaban groups was treated in error with warfarin and therefore included in the warfarin group. aSubjects receiving warfarin pretreatment underwent a 1-week washout/dose adjustment (range, 3-14 days) until a target international normalized ratio (INR) $<2.0$ was achieved prior to entering the treatment period.

prevention in non-valvular AF, several novel oral agents that are either direct thrombin or factor Xa inhibitors are under development. ${ }^{15-19}$ Apixaban, a potent, oral, reversible, direct, and highly selective factor $\mathrm{Xa}$ inhibitor, has a predictable pharmacokinetic and pharmacodynamic profile, does not require routine monitoring, is not affected by food intake, and has limited drug interactions. ${ }^{20-25}$ It has rapid absorption and a half-life of approximately $12 \mathrm{~h} .{ }^{26}$ Apixaban exposure was similar in Japanese and Caucasian subjects matched for weight, age, and smoking status. ${ }^{27}$ The ongoing phase III program for apixaban for stroke prevention in patients with nonvalvular $\mathrm{AF}^{28,29}$ includes the ARISTOTLE trial, which is comparing apixaban with warfarin in $>18,000$ patients, and the AVERROES trial, which is comparing apixaban with aspirin in 5,600 patients. Recently, it was announced that the
AVERROES trial has been stopped early because of clear evidence of a significant benefit of apixaban compared with aspirin with no significant difference in the risk of major bleeding. ${ }^{30}$

We report here the results of ARISTOTLE-J, a phase II randomized, partially blind, active-controlled study in Japanese patients with non-valvular AF, the primary objective of which was to assess 2 doses of apixaban vs. warfarin for the composite safety endpoint of major and clinically relevant non-major (CRNM) bleeding during a treatment period of 12 weeks. The significance of this study is 2 -fold. First, this phase II study was undertaken at the same time that the large, ongoing global phase III ARISTOTLE trial was being conducted. This approach might help to minimize "drug lag" in the evaluation and potential introduction of apixaban into 
Japanese clinical practice. Historically, the time elapsed between a drug's approval in Europe or North America and introduction in Japan has been approximately 2.5 years. ${ }^{31}$ Second, this is the only phase II study conducted with apixaban in patients with non-valvular AF, and thus it provides initial insights into the potential utility of apixaban vs. warfarin for stroke prevention in this patient population before data from the larger, longer-term phase III ARISTOTLE trial become available.

\section{Methods}

\section{Patients}

This study was conducted at 23 Japanese sites. All subjects gave written informed consent prior to participation. Patients aged $\geq 20$ years with a history of documented non-valvular AF and at least 1 additional risk factor for stroke were enrolled. Instances of AF (confirmed by electrocardiogram, Holter recording, or intracardiac electrogram) were required to be at least $1 \mathrm{~min}$ in duration and to have occurred on 2 separate occasions, at least 2 weeks apart, within 12 months prior to enrollment. Study participants had at least 1 of the following stroke risk factors: age $\geq 75$ years, congestive heart failure (left ventricular ejection fraction $\leq 40 \%$ ), hypertension requiring medication, diabetes mellitus deemed to require treatment based on the physician's discretion, or history of cerebral infarction or transient ischemic attack (TIA).

Study exclusion criteria included: recent cerebral infarction (including TIA); valvular heart disease; sick sinus syndrome or severe conduction disturbance; non-cardiogenic stroke requiring ASA $>100 \mathrm{mg} /$ day or concomitant ASA and antiplatelet agents; contraindications for warfarin use (eg, thrombocytopenic purpura, suspected intracranial bleeding, bleeding tendency due to angiopathy, blood coagulation disorder such as hemophilia, recent major operation, peptic ulcer, or dementia); severe or refractory hypertension; New York Heart Association class IV heart failure; current thrombocytopenia (platelet count $<100 \times 10^{9} / \mathrm{L}$ or hemoglobin $<10 \mathrm{~g} / \mathrm{dl}$ ); liver function test abnormalities (alanine aminotransferase or aspartate aminotransferase $\geq 2 \times$ upper limit of normal [ULN]) or renal dysfunction (creatinine clearance $<25 \mathrm{ml} / \mathrm{min}$ by Cockcroft Gault calculation); known or suspected hereditary bleeding tendencies; and scheduled electrical, pharmacological, or surgical cardioversion during the treatment period.

\section{Study Design}

This was a randomized, partially blinded study comparing 2 double-blinded doses of apixaban with open-label warfarin (Figure 1). Subjects were classified as warfarin naïve if they had never received or had received $\leq 30$ consecutive days of warfarin or another vitamin $\mathrm{K}$ antagonist in the past. During a 1-week observation period preceding week 0 (allowable range, 3-14 days), patients who had been receiving warfarin pretreatment had their warfarin dose adjusted or discontinued to achieve an international normalized ratio (INR) $<2.0$ before entering the 12-week treatment period.

On the first day of study drug dosing (week 0), patients were randomized in a 1:1:1 fashion to receive 12 weeks of double-blinded apixaban $2.5 \mathrm{mg}$ b.i.d., or $5 \mathrm{mg}$ b.i.d., or openlabel warfarin titrated to a target INR of 2.0-3.0 in patients aged $\leq 70$ years and $2.0-2.6$ in patients aged $>70$ years. The randomization assignment method ${ }^{32}$ incorporated trial site and warfarin status (experienced or naïve) as factors. Subjects were evaluated at study visits at weeks $1,2,4,8$, and 12 (or at study discontinuation if applicable) for bleeding and throm- boembolic events, other adverse events (AE), and vital signs. Blood samples taken at clinic visits were analyzed by central laboratories for pharmacokinetics, pharmacodynamics (including INR), and clinical laboratory parameters. Follow up was conducted by phone, when possible, 30 days after their last study visit.

The study was conducted according to the Declaration of Helsinki and in compliance with the International Conference on Harmonization and Good Clinical Practice guidelines. All local regulatory requirements and sponsoring company policies were followed. An independent data safety monitoring board advised the study steering committee and study sponsor.

\section{Study Endpoints}

The primary study endpoint was a composite of major bleeding and CRNM bleeding events. Secondary endpoints included major and CRNM bleeding events considered separately, and a composite of total bleeding events (including minor events). The study also included 3 efficacy endpoints: composite of stroke or systemic embolism; composite of stroke, systemic embolism, or all-cause death; and composite of myocardial infarction (MI) or all-cause death. An independent blinded endpoint committee adjudicated all reported bleeding and efficacy events.

Bleeding events were defined using International Society on Thrombosis and Haemostasis (ISTH) criteria. ${ }^{33}$ Major bleeds were defined as acute, clinically overt, and with 1 or more of the following: a decrease in hemoglobin $\geq 2 \mathrm{~g} / \mathrm{dl}$ over a 24-h period; bleeding requiring transfusion of $\geq 2$ units of packed red blood cells; or bleeding in a critical site (intracranial, intraspinal, intraocular [not conjunctival], pericardial, intra-articular, intramuscular with compartment syndrome, retroperitoneal); or bleeding that was fatal. CRNM bleeding events were defined as acute or subacute, clinically overt, not major, and leading to hospital admission for bleeding, physician-guided medical or surgical treatment for bleeding, or a change in antithrombotic therapy. Minor bleeding was defined as acute clinically overt events not meeting the criteria for either major or CRNM bleeding.

\section{Pharmacokinetic and Pharmacodynamic Analyses}

Blood samples were collected from the apixaban patients at time 0 (pre-dose) and at 1-3 and 3-4h after dosing in weeks 1 and 8 of treatment, and pharmacokinetic analyses were performed by Alta Analytical Laboratory (El Dorado Hills, CA, USA). Prothrombin time (PT), PT-INR and activated partial thromboplastin time (aPTT) were assessed by SRL Medisearch Inc (USA) and anti-Xa assay was conducted by Esoterix Clinical Trial Services (Engelwood, CO, USA) using a Rotachrom Heparin Assay.

\section{Statistical Analysis}

Target sample size was calculated taking into account the estimated accuracy of the expected difference in the incidence of major and CRNM bleeds between the warfarin (5-8\% for the assumption of true incidence) and apixaban (4-9\% for the assumption of true incidence) groups. With 70 subjects per treatment group (for a total of 210), the half-length of the 95\% confidence intervals (CI) for the difference in proportions of major/CRNM bleeds between each apixaban group and the warfarin group would be 7-9\%. In addition, assuming the true incidence of total bleeding would be $16-17 \%$ with warfarin and $10-13 \%$ with apixaban, 70 subjects per group would give a half-length of the $95 \% \mathrm{CI}$ for the difference in 


\begin{tabular}{|c|c|c|c|}
\hline Baseline characteristic & $\begin{array}{c}\text { Apixaban } \\
2.5 \mathrm{mg} \text { b.i.d. } \\
(\mathrm{n}=74)\end{array}$ & $\begin{array}{c}\text { Apixaban } \\
5 \mathrm{mg} \text { b.i.d. } \\
(\mathrm{n}=74)\end{array}$ & $\begin{array}{c}\text { Warfarin } \\
(n=74)\end{array}$ \\
\hline Age (mean) (years) & 69.3 & 70.0 & 71.7 \\
\hline Male, n (\%) & $63(85.1)$ & $61(82.4)$ & $60(81.1)$ \\
\hline Body weight (mean) (kg) & 67.6 & 65.0 & 64.7 \\
\hline Body mass index (mean) $\left(\mathrm{kg} / \mathrm{m}^{2}\right)$ & 25.3 & 24.5 & 24.4 \\
\hline Blood pressure, systolic/diastolic (mean) (mmHg) & $131 / 77$ & $125 / 74$ & $126 / 75$ \\
\hline Warfarin experienced ${ }^{\star}, \mathrm{n}(\%)$ & $61(84.7)$ & $62(87.3)$ & $63(84.0)$ \\
\hline Concomitant ASA use during study*, $n(\%)$ & $15(20.8)$ & $20(28.2)$ & $19(25.3)$ \\
\hline $\mathrm{CHADS}_{2}$ score $^{\star \star}$ (mean) & 1.8 & 2.1 & 1.9 \\
\hline $0, \mathrm{n}(\%)$ & $1(1.4)$ & $1(1.4)$ & $1(1.4)$ \\
\hline $1, \mathrm{n}(\%)$ & $31(41.9)$ & $26(35.1)$ & $36(48.6)$ \\
\hline $2, \mathrm{n}(\%)$ & $25(33.8)$ & $24(32.4)$ & $16(21.6)$ \\
\hline$\geq 3, \mathrm{n}(\%)$ & $17(23.0)$ & $23(31.1)$ & $21(28.4)$ \\
\hline Cardiac failure congestive, $\mathrm{n}(\%)$ & $0(0)$ & $1(1.4)$ & $2(2.7)$ \\
\hline Hypertension, n (\%) & $61(82.4)$ & $61(82.4)$ & $63(85.1)$ \\
\hline Age $\geq 75$ years, $n(\%)$ & $22(29.7)$ & $23(31.1)$ & $23(31.1)$ \\
\hline Diabetes mellitus, n (\%) & $21(28.4)$ & $16(21.6)$ & $15(20.3)$ \\
\hline History of cerebral infarction (including TIA), n (\%) & $16(21.6)$ & $26(35.1)$ & $20(27.0)$ \\
\hline
\end{tabular}

${ }^{*}$ Warfarin experience (\%) and concomitant ASA use (\%) are based on the safety population (all treated patients). ${ }^{\star *} \mathrm{CHADS}_{2}$ : congestive heart failure, hypertension, age $\geq 75$ years, diabetes (1 point each), stroke (2 points).

ASA, acetylsalicylic acid; TIA, transient ischemic attack.

proportions of all bleeds between each apixaban group and the warfarin group of $11.1-11.8 \%$.

The safety population comprised all randomized patients who received at least 1 dose of the study drug. Efficacy determinations were based on the intent-to-treat population, which included all randomized patients. The proportions of patients with safety and efficacy endpoint events and the corresponding $95 \%$ CI were calculated for each treatment group, as were the differences in proportions between each apixaban dose group and the warfarin group. Due to the relatively small number of patients per group, no formal statistical testing was conducted, and therefore P-values were not calculated.

The analyses of bleeding endpoints and all $\mathrm{AE}$ included events that occurred during the "treatment period", defined as starting on the day of first dosing until 2 days after discontinuation of the study drug. Analyses of efficacy endpoints were based on the "intended treatment period", defined as starting on the day of randomization and ending either 2 days after the last dose of study drug or at the week 12 visit, whichever came last.

\section{Results}

\section{Patient Disposition and Baseline Characteristics}

Of the 245 patients assessed for eligibility, 222 were randomized (74 per treatment group) and were included in the efficacy analysis set (Figure 1). A total of 4 patients discontinued the study without receiving treatment, and 2 randomized to apixaban were treated with warfarin in error and were therefore included in the warfarin treatment group. The remaining 218 patients were included in the safety analysis.

Baseline characteristics were similar across the treatment groups (Table 1). A somewhat lower proportion of patients in the apixaban $2.5 \mathrm{mg}$ b.i.d. group received concomitant aspirin than in the other 2 groups. There were minor differences in the pattern of stroke risk factors: for example, a slightly higher proportion of patients randomized to warfarin had con- gestive heart failure or hypertension; diabetes mellitus was most common in the apixaban $2.5 \mathrm{mg}$ b.i.d. group; and prior stroke or was most common in the apixaban $5 \mathrm{mg}$ b.i.d. group. Overall, $44.6 \%$ of patients had 1 additional risk factor for stroke, $54.1 \%$ of patients had 2 or more, and 3 patients $(1.4 \%$; 1 in each group) had none. Mean $\mathrm{CHADS}_{2}$ scores were 1.8, 2.1, and 1.9 in the apixaban 2.5 and $5 \mathrm{mg}$ b.i.d. and warfarin groups, respectively. More than $80 \%$ of the patients who received study treatment were classified as warfarin experienced at baseline in each group, and 21-28\% received concomitant ASA during the study.

\section{Treatment Compliance and INR Control}

The median duration of treatment was 85 days in each apixaban group and 84 days in the warfarin group. INR was generally well controlled in the warfarin group during the 12-week treatment period: overall $\geq 60 \%$ of patients had INR within the 2.0-3.0 range for $60 \%$ of the treatment period according to Rosendaal's linear interpolation, ${ }^{34}$ regardless of whether they were older or younger than 70 years. The proportion was $\sim 70 \%$ among patients who were warfarin experienced and $\sim 33 \%$ among those who were warfarin naïve. In patients aged $\geq 70$ years, $\sim 70 \%$ had INR in the range 1.6-2.6, which is the suggested INR range in the Japanese guidelines for management of stroke for this age group.,9

\section{Primary Endpoint}

The composite of major or CRNM bleeding events occurred in 1 of 72 patients $(1.4 \%$; 95\% CI, $0.1-6.9)$ in the apixaban $2.5 \mathrm{mg}$ b.i.d. group, 1 of $71(1.4 \%$; $95 \% \mathrm{CI}, 0.1-7.0)$ in the apixaban $5 \mathrm{mg}$ b.i.d. group, and 4 of 75 (5.3\%; 95\%CI, 1.812.7 ) in the warfarin group (Figure 2). Only one major bleeding event occurred, a subarachnoid hemorrhage in a patient in the warfarin arm. This was in an 80-year-old man who had received therapy with ticlopidine for the past 7 years and warfarin for the past 3 years. The cause of the subarachnoid hemorrhage was unknown and although the INR was gener- 
Apixaban 2.5 mg b.i.d. $(n=72)$

Apixaban 5 mg b.i.d. $(n=71)$

$14 \quad \square$ Warfarin $(\mathrm{n}=75)$

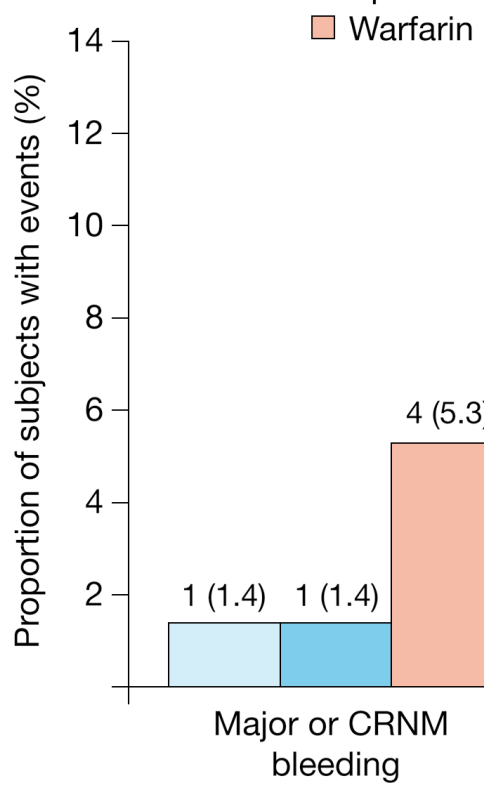

Figure 2. Proportion of patients with bleeding events (per International Society on Thrombosis and Haemostasis [ISTH] criteria) during treatment. Data above the bars represent the number of patients (proportion of patients [\%]). CRNM, clinically relevant non-major.

Table 2. Number of Patients With Minor Bleeding Events Apixaban Apixaban $2.5 \mathrm{mg}$ b.i.d. $5 \mathrm{mg}$ b.i.d. Warfarin $(n=72) \quad(n=71) \quad(n=75)$

\section{Epistaxis}

Blood urine present

Gingival bleeding

Hematuria

Hematochezia

Hemorrhoidal bleeding

Contusion

Retinal hemorrhage

Mouth bleeding

Bite mark

Traumatic hemorrhage

Eczema nummular

Hemorrhage subcutaneous

Subconjunctival hemorrhage

Purpura

\begin{tabular}{lll}
3 & $4^{*}$ & 3 \\
1 & 3 & 3 \\
1 & 1 & 0 \\
0 & $2^{*}$ & 1 \\
0 & 2 & 0 \\
1 & 1 & 0 \\
0 & 1 & 1 \\
0 & 0 & 1 \\
0 & 0 & 1 \\
0 & 1 & 0 \\
0 & 1 & 0 \\
1 & 0 & 0 \\
1 & 0 & 0 \\
0 & 1 & 0 \\
0 & 1 & 0 \\
\hline
\end{tabular}

${ }^{*}$ One patient in the apixaban $5 \mathrm{mg}$ b.i.d. group had an epistaxis and a hematuria event and is counted twice in Table 2.

ally well controlled near the time of the event and during the study the investigator considered the event to be related to warfarin. Regarding CRNM bleeding, the 1 event occurring in the apixaban $2.5 \mathrm{mg}$ b.i.d. arm consisted of epistaxis; for apixaban $5 \mathrm{mg}$ b.i.d. there was 1 case of gastrointestinal hemorrhage; and for warfarin there was 1 epistaxis event, 1 blood in urine event, and 1 conjunctival hemorrhage.

The incidence of minor bleeding was low (Table 2). The most frequent cause of minor bleeding was epistaxis ( 3 cases in apixaban $2.5 \mathrm{mg}$ b.i.d., 4 in apixaban $5 \mathrm{mg}$ b.i.d., and 3 in the warfarin group). As indicated in Table 2, although there were numerically more minor bleeding events reported in the apixaban $5 \mathrm{mg}$ b.i.d. group, this was primarily accounted for by single occurrences of various minor bleeding events, such as hemorrhoidal bleeding, contusion, and purpura. Because of these findings for minor bleeding events, the incidence of total bleeding was proportionally highest $(23.9 \%)$ in the apixaban $5 \mathrm{mg}$ b.i.d. group compared with $12.5 \%$ in the apixaban $2.5 \mathrm{mg}$ b.i.d. group and $17.3 \%$ with warfarin.

There were no differences in the proportion of patients with total bleeding events when stratified by gender, number of stroke risk factors, history of diabetes mellitus, cerebral infarction, cardiac failure, or hypertension. As expected, older patients had more total bleeding events than younger patients; in the apixaban $2.5 \mathrm{mg}$ b.i.d. arm the proportion of patients with total bleeds was higher among those aged $\geq 65$ vs. $<65$ years ( 15.1 vs. $5.3 \%$, respectively); in the apixaban $5 \mathrm{mg}$ b.i.d. arm the proportion was higher in those aged $\geq 75$ vs. $<75$ years ( 38.1 vs. $18.0 \%$, respectively); similarly, in the warfarin arm total bleeds occurred in $32.0 \%$ vs. $10.0 \%$ in the $\geq 75$ and $<75$ age groups, respectively.

\section{Stroke, Systemic Embolism, MI, or All-Cause Death}

There were no incidences of stroke, systemic embolism, MI, or all-cause death in either apixaban group. In the warfarin group, 3 patients $(4.1 \%)$ had stroke events: a subarachnoid hemorrhage in 1 patient, considered to be treatment related although INR was well controlled, and ischemic stroke in 2 patients, 1 with INR 2.5 on admission and 1 with INR 2.18 . Baseline risk factors for these 3 patients in the warfarin group were age $\geq 75$ years ( 2 subjects), history of cerebral infarc- 


\begin{tabular}{|c|c|c|c|}
\hline & $\begin{array}{c}\text { Apixaban } \\
2.5 \mathrm{mg} \text { b.i.d. } \\
(\mathrm{n}=72)\end{array}$ & $\begin{array}{c}\text { Apixaban } \\
5 \text { mg b.i.d. } \\
(\mathrm{n}=71)\end{array}$ & $\begin{array}{c}\text { Warfarin } \\
(n=75)\end{array}$ \\
\hline \multicolumn{4}{|l|}{ Adverse events, $\mathbf{n}(\%)$} \\
\hline All cause & $37(51.4)$ & $42(59.2)$ & $35(46.7)$ \\
\hline Treatment related ${ }^{*}$ & $17(23.6)$ & $17(23.9)$ & $10(13.3)$ \\
\hline \multicolumn{4}{|c|}{ Serious adverse events, $\mathbf{n}(\%)$} \\
\hline All cause & $1(1.4)$ & $5(7.0)$ & $4(5.3)$ \\
\hline Treatment related $^{*}$ & $0(0)$ & $0(0)$ & $1(1.3)$ \\
\hline \multicolumn{4}{|c|}{ Discontinuations due to adverse events, $\mathbf{n}(\%)$} \\
\hline All cause & $4(5.6)$ & $4(5.6)$ & $4(5.3)$ \\
\hline Treatment related $^{*}$ & $4(5.6)$ & $2(2.8)$ & $1(1.3)$ \\
\hline \multicolumn{4}{|c|}{ Deaths due to serious adverse events, $n(\%)$} \\
\hline All cause & $0(0)$ & $0(0)$ & $0(0)$ \\
\hline Treatment related $^{*}$ & $0(0)$ & $0(0)$ & $0(0)$ \\
\hline \multicolumn{4}{|c|}{ Most frequent adverse events (>5\%) (all cause), $n(\%)$} \\
\hline Nasopharyngitis & 8 (11.1) & $8(11.3)$ & $7(9.3)$ \\
\hline Epistaxis & $4(5.6)$ & $4(5.6)$ & $4(5.3)$ \\
\hline Blood urine present & $1(1.4)$ & $3(4.2)$ & $4(5.3)$ \\
\hline
\end{tabular}

*Includes adverse events whose relationship to the study drug were certain, probable, or possible according to investigators.

tion including TIA (2 subjects), hypertension ( 2 subjects), and diabetes mellitus (1 subject). One patient $(1.4 \%)$ in the warfarin group experienced an event that was adjudicated as a TIA. No MI or deaths occurred in the warfarin group.

\section{AE}

The proportion of patients with $\mathrm{AE}$ was comparable among the treatment groups, as summarized in Table $\mathbf{3}$, as were proportions with serious $\mathrm{AE}$, discontinuations due to $\mathrm{AE}$, and most frequent all-cause AE. The most frequently reported treatment-related $\mathrm{AE}$ were epistaxis $(4.2 \%$ and $2.8 \%$ in the apixaban 2.5 and $5 \mathrm{mg}$ b.i.d. groups, respectively, vs. $5.3 \%$ in the warfarin group), and blood in urine $(0.0 \%$ and $4.2 \%$ vs. $4.0 \%$, respectively). Most $\mathrm{AE}$ were mild or moderate in severity. Four severe AE ( 2 in the apixaban $5 \mathrm{mg}$ b.i.d. group and 2 in the warfarin group) were reported. Two were considered treatment related (1 case of trigeminal neuralgia in the apixaban $5 \mathrm{mg}$ b.i.d. group and 1 subarachnoid hemorrhage in the warfarin group). Overall, 12 patients (5.5\%) discontinued due to $\mathrm{AE}$ (4 in each group).

Occurrence of laboratory abnormalities was similar among all 3 treatment groups. No patients in any of the groups had levels of alanine aminotransferase or aspartate aminotransferase $>3 \times$ ULN . One patient in the apixaban $2.5 \mathrm{mg}$ group had total bilirubin $>2 \times$ ULN at week 8 , but it returned to normal in 1 week after discontinuation of concomitant rosuvastatin treatment. Concurrent elevations of aminotransferases $>3 \times \mathrm{ULN}$ and total bilirubin $>1.5 \times \mathrm{ULN}$ on the same day were not observed in any treatment group. There were no discontinuations that were related to elevation in liver function test results.

\section{Pharmacokinetics and Pharmacodynamics}

Plasma concentrations of apixaban increased over the 3 time points sampled (1,2, and $4 \mathrm{~h}$ after dosing), were proportional to dose, and similar in week 1 and week 8 . Anti-Xa activity correlated closely with apixaban concentration, whereas the correlation was weak with PT, PT-INR, and aPTT.

\section{Discussion}

Many important multinational studies have not included patients in Japan, partly because the regulatory system in Japan is different and also due to a perception that cardiovascular event rates are lower and bleeding complications more frequent in Japanese than Western patients. ${ }^{35}$ This has contributed, in part, to a "drug lag" wherein the evaluation and approval of new agents are delayed in Japan by approximately 2.5 years compared with other countries. ${ }^{31}$ For the ongoing development program evaluating the novel factor $\mathrm{Xa}$ inhibitor apixaban for stroke prevention in non-valvular AF, 2 studies have enrolled patients in Japan: ARISTOTLE-J, the phase II study presented here, and ARISTOTLE, the ongoing global phase III trial in $>18,000$ patients. ${ }^{29}$ The approach of conducting ARISTOTLE-J concurrently with the larger, longer-term ARISTOTLE trial might facilitate minimizing "drug lag" in the evaluation and potential availability of apixaban to clinical practice in Japan.

ARISTOTLE-J was a randomized, partially blinded study in which we compared the effect of 2 doses of apixaban ( $2.5 \mathrm{mg}$ and $5 \mathrm{mg}$ b.i.d.) with adjusted-dose warfarin on the composite of major or CRNM bleeding during a 12-week treatment period in Japanese patients with non-valvular AF and 1 or more additional stroke risk factors. The primary endpoint focused on safety in Japanese patients in this phase II study. Larger phase III studies of longer duration are needed to evaluate efficacy and confirm safety. The number of patients exposed to apixaban in the phase II study will constitute approximately $40 \%$ of the overall apixaban safety database in Japanese patients from the phase II and III programs.

Overall, we found only a few cases of the primary endpoint (Figure 2): each dose of apixaban was associated with only 1 case of major or CRNM bleeding (1.4\%) compared with 4 cases with warfarin $(5.3 \%)$. No major bleeding events occurred in the apixaban groups, whereas 1 case $(1.3 \%)$ of subarachnoid hemorrhage occurred in the warfarin group. The incidence of minor bleeding events was also low, accounted for by several cases of epistaxis in each group and single 
occurrences of various other events, such as gingival bleeding (Table 2). The low rates of bleeding we observed over the 12 weeks after initiation of anticoagulation therapy are notable given that bleeding rates tend to be higher during that period. ${ }^{36}$

The number of events was too low to determine whether they could have been affected by minor differences in baseline demographics (Table 1); however, we think this is unlikely. Although concomitant aspirin use was lower in the apixaban $2.5 \mathrm{mg}$ b.i.d. group, it was similar in the apixaban $5 \mathrm{mg}$ b.i.d. and warfarin groups. Hypertension, older age, and history of stroke are known to be risk factors for bleeding as well as for stroke. ${ }^{37}$ The first 2 of these were present in relatively similar proportions of patients between treatments. A history of stroke was lowest in the apixaban $2.5 \mathrm{mg}$ group but highest in the apixaban $5 \mathrm{mg}$ group. Thus, the rate of events does not seem to consistently correlate with these factors.

Apixaban was well tolerated in this 12-week study. Most AE were either mild or moderate, with few leading to discontinuation. This was also the case in patients treated with open-label warfarin, $80 \%$ of whom were warfarin experienced but had undergone a washout period prior to randomization. In addition, we found no elevations of aminotransferases $>3 \times$ ULN in any of the 3 groups.

Of the agents in development for stroke prevention in $\mathrm{AF}$, phase III results have been published only for dabigatran etexilate, an oral direct thrombin inhibitor. In the RE-LY trial, dabigatran was shown to be superior for stroke prevention, with bleeding rates similar to those with warfarin at a higher dabigatran dose; a lower dose of dabigatran showed similar stroke rates to warfarin, with lower bleeding. ${ }^{18}$ In RE-LY, there was a greater rate of dyspepsia (including abdominal pain) in both dabigatran groups compared with warfarin, and a greater rate of treatment discontinuations $(\sim 15 \%$ vs. $10 \%$ at 1 year and $21 \%$ vs. $17 \%$ at 2 years for dabigatran and warfarin, respectively). MI, although infrequent overall, was more common in the dabigatran groups $(0.72 \%$ and $0.74 \%)$ vs. warfarin $(0.53 \%) .{ }^{18}$ In our smaller and shorter duration phase II study, we observed no imbalance in discontinuations and no MI.

In addition to the short duration of the present study, another potential limitation was the use of open-label warfarin. However, the trial design for this phase II study is similar to that used in RE-LY. Furthermore, bleeding and cardiovascular endpoints reported by investigators were centrally adjudicated in a blinded fashion.

In summary, ARISTOTLE-J results show that in Japanese patients with non-valvular AF, oral administration of apixaban $2.5 \mathrm{mg}$ and $5 \mathrm{mg}$ b.i.d. was well tolerated, with lower rates of major/CRNM bleeding than warfarin over 12 weeks. No stroke or systemic embolic events occurred in the apixaban groups. These phase II results add to the emerging clinical trial data on apixaban in patients with non-valvular AF. The phase III AVERROES trial of apixaban compared with aspirin in warfarin-intolerant or warfarin-unsuitable patients was recently stopped early because of a significant benefit in patients randomized to apixaban. Patients randomized to apixaban had a significant reduction in the risk of stroke or systemic embolism compared with patients randomized to aspirin. There was no significant difference between groups in the risk of major bleeding. Thus, results from AVERROES suggest that for AF patients unsuitable for warfarin, apixaban has a favorable risk to benefit profile. ${ }^{30}$ For warfarin-tolerant patients, data from our Japanese patient study provide initial insights into the potential clinical utility of apixaban prior to availability of data from the large, ongoing global phase III ARISTOTLE trial, which also includes patients from Japan.

\section{Acknowledgments}

In addition to the ARISTOTLE-J Study Group, the authors gratefully acknowledge the contributions of: Yasuo Ikeda, MD, Waseda University, Tokyo; Shinya Goto, MD, Tokai University, Kanagawa; Joseph G. Gaugas, PhD, Pfizer Japan Inc, Tokyo; and Nilo B Cater, MD, Pfizer Inc, New York. Professional medical writing support was provided by Keith Day, PhD, of PPSI and was funded by Pfizer Inc and Bristol-Myers Squibb.

\section{Disclosures}

S. Ogawa: consultant to Teijin Pharma Ltd, Bayer Yakuhin Ltd, and sanofi-aventis. Y. Shinohara: consultant to sanofi-aventis, Otsuka, Bayer, and Schering Plough. K. Kanmuri: employee of Pfizer Inc.

\section{References}

1. Go AS, Hylek EM, Phillips KA, Chang Y, Henault LE, Selby JV, et al. Prevalence of diagnosed atrial fibrillation in adults: National implications for rhythm management and stroke prevention: The AnTicoagulation and Risk Factors in Atrial Fibrillation (ATRIA) Study. JAMA 2001; 285: 2370-2375.

2. Ohsawa M, Okayama A, Okamura T, Itai K, Nakamura M, Tanno K, et al. Mortality risk attributable to atrial fibrillation in middle-aged and elderly people in the Japanese general population: Nineteenyear follow-up in NIPPON DATA80. Circ J 2007; 71: 814-819.

3. Tanizaki Y, Kiyohara Y, Kato I, Iwamoto H, Nakayama K, Shinohara N, et al. Incidence and risk factors for subtypes of cerebral infarction in a general population: The Hisayama study. Stroke 2000; 31: 2616-2622.

4. Wolf PA, Abbott RD, Kannel WB. Atrial fibrillation as an independent risk factor for stroke: The Framingham Study. Stroke 1991; 22: 983-988.

5. Hart RG, Pearce LA, Aguilar MI. Adjusted-dose warfarin versus aspirin for preventing stroke in patients with atrial fibrillation. Ann Intern Med 2007; 147: 590-592.

6. Fuster V, Ryden LE, Cannom DS, Crijns HJ, Curtis AB, Ellenbogen $\mathrm{KA}$, et al. ACC/AHA/ESC 2006 guidelines for the management of patients with atrial fibrillation-executive summary: A report of the American College of Cardiology/American Heart Association Task Force on Practice Guidelines and the European Society of Cardiology Committee for Practice Guidelines (Writing Committee to Revise the 2001 Guidelines for the Management of Patients with Atrial Fibrillation). Eur Heart J 2006; 27: 1979-2030.

7. Singer DE, Albers GW, Dalen JE, Fang MC, Go AS, Halperin JL, et al. Antithrombotic therapy in atrial fibrillation: American College of Chest Physicians Evidence-Based Clinical Practice Guidelines (8th Edition). Chest 2008; 133: 546S-592S.

8. Shinohara Y, Yamaguchi T. Outline of the Japanese Guidelines for the Management of Stroke 2004 and subsequent revision. Int J Stroke 2008; 3: 55-62.

9. Joint Study Group of the Japanese Circulation Society, Japanese College of Cardiology, Japanese Society of Electrocardiology, and the Japanese Heart Rhythm Society. Guidelines for pharmacotherapy of arrhythmias. Circ $J$ 2008; 72(Suppl): 1639-1658.

10. JCS Joint Working Group. Guidelines for pharmacotherapy of atrial fibrillation (JCS 2008): Digest version. Circ J 2010; 74: 24792500.

11. Ogawa S, Yamashita T, Yamazaki T, Aizawa Y, Atarashi H, Inoue $\mathrm{H}$, et al. Optimal treatment strategy for patients with paroxysmal atrial fibrillation: J-RHYTHM Study. Circ J 2009; 73: 242-248.

12. Waldo AL, Becker RC, Tapson VF, Colgan KJ. Hospitalized patients with atrial fibrillation and a high risk of stroke are not being provided with adequate anticoagulation. J Am Coll Cardiol 2005; 46: $1729-1736$

13. Guo GB, Chang HW, Chen MC, Yang CH. Underutilization of anticoagulation therapy in chronic atrial fibrillation. Jpn Heart J 2001; 42: $55-65$.

14. Sato H, Ishikawa K, Kitabatake A, Ogawa S, Maruyama Y, Yokota $\mathrm{Y}$, et al. Low-dose aspirin for prevention of stroke in low-risk patients with atrial fibrillation: Japan Atrial Fibrillation Stroke Trial. Stroke 2006; 37: 447-451.

15. Lip GY, Rasmussen LH, Olsson SB, Jensen EC, Persson AL, Eriksson U, et al. Oral direct thrombin inhibitor AZD0837 for the prevention of stroke and systemic embolism in patients with nonvalvular atrial fibrillation: A randomized dose-guiding, safety, and 
tolerability study of four doses of AZD0837 vs. vitamin K antagonists. Eur Heart J 2009; 30: 2897-2907.

16. Weitz JI, Connolly SJ, Kunitada S, Jin J, Patel I. Randomized, parallel group, multicenter, multinational study evaluating safety of DU$176 \mathrm{~b}$ compared with warfarin in subjects with non-valvular atrial fibrillation. Blood 2009; 112: 33

17. Yasaka $\mathrm{M}$, Inoue $\mathrm{H}$, Kawai $\mathrm{Y}$, Yamaguchi $\mathrm{T}$, Uchiyama $\mathrm{S}$, Matsumoto M, et al. Randomized, parallel group, warfarin control, multicenter phase II study evaluating safety of DU-176b in Japanese subjects with non-valvular atrial fibrillation (NVAF). J Thromb Haemost 2009; 7: PP-WE-196.

18. Connolly SJ, Ezekowitz MD, Yusuf S, Eikelboom J, Oldgren J, Parekh A, et al. Dabigatran versus warfarin in patients with atrial fibrillation. N Engl J Med 2009; 361: 1139-1151.

19. ROCKET AF Study Investigators. Rivaroxaban-once daily, oral, direct factor $\mathrm{Xa}$ inhibition compared with vitamin $\mathrm{K}$ antagonism for prevention of stroke and Embolism Trial in Atrial Fibrillation: Rationale and design of the ROCKET AF study. Am Heart J 2010; 159: $340-347$.

20. Wong PC, Crain EJ, Xin B, Wexler RR, Lam PY, Pinto DJ, et al. Apixaban, an oral, direct and highly selective factor Xa inhibitor: In vitro, antithrombotic and antihemostatic studies. J Thromb Haemost 2008; 6: 820-829.

21. Vakkalagadda B, Frost C, Wang J, Nepal S, Schuster A, Zhang D, et al. Effect of rifampin on the pharmacokinetics of apixaban, an oral director inhibitor of factor Xa (abstract). J Clin Pharamcol 2009; 49: $1091-1130$.

22. Upreti VV, Song Y, Wang J, Farmer M, Pursley JM, Li T, et al. Effect of famotidine on the pharmacokinetics of apixaban, an oral direct inhibitor of factor Xa, in healthy subjects (abstract). J Clin Pharmacol 2009; 49: 1091-1130.

23. Frost C, Yu Z, Shenker A, Nepal S. Food does not affect the pharmacokinetics of apixaban, an oral, factor Xa inhibitor. Can J Clin Pharmacol 2008; 15: e469.

24. Frost C, Wang J, Nepal S, Schuster A, Zhang D, Yu Z, et al. Effect of ketoconazole and diltiazem on the pharmacokinetics of apixaban, an oral direct factor Xa inhibitor (abstract). J Clin Pharmacol 2009; 49: $1091-1130$.

25. Carreiro J, Ansell J. Apixaban, an oral direct Factor Xa inhibitor: Awaiting the verdict. Expert Opin Investig Drugs 2008; 17: 1937 1945.

26. Raghavan N, Frost CE, Yu Z, He K, Zhang H, Humphreys WG, et al. Apixaban metabolism and pharmacokinetics following oral administration to humans. Drug Metab Dispos 2009; 37: 74-81.

27. Yamahira N, Imai Y, Yu Z, Wastall P, Wang J, Frost C, et al. A placebo-controlled, ascending multiple-dose study to evaluate the safety, tolerability, pharmacokinetics, and pharmacodynamics of apixaban in healthy Japanese subjects. Can J Clin Pharmacol 2008; 15: e719.

28. Eikelboom JW, O’Donnell M, Yusuf S, Diaz R, Flaker G, Hart R, et al. Rationale and design of AVERROES: Apixaban versus acetylsalicylic acid to prevent stroke in atrial fibrillation patients who have failed or are unsuitable for vitamin $\mathrm{K}$ antagonist treatment. Am Heart J 2010; 159: 348-353.

29. Lopes RD, Alexander JH, Al Khatib SM, Ansell J, Diaz R, Easton $\mathrm{JD}$, et al. Apixaban for reduction in stroke and other ThromboemboLic events in atrial fibrillation (ARISTOTLE) trial: Design and rationale. Am Heart J 2010; 159: 331-339.

30. AVERROES: Apixaban versus acetylsalicylic acid (ASA) to prevent strokes. http://www.escardio.org/congresses/esc-2010/congress-reports/ Pages/708-3-AVERROES.aspx (accessed 31 August, 2010).

31. Ichimaru K, Toyoshima S, Uyama Y. Effective global drug development strategy for obtaining regulatory approval in Japan in the context of ethnicity-related drug response factors. Clin Pharmacol Ther 2010; 87: 362-366.

32. Pocock SJ, Simon R. Sequential treatment assignment with balancing for prognostic factors in the controlled clinical trial. Biometrics 1975; 31: $103-115$.

33. Schulman S, Kearon C. Definition of major bleeding in clinical investigations of antihemostatic medicinal products in non-surgical patients. J Thromb Haemost 2005; 3: 692-694.

34. Rosendaal FR, Cannegieter SC, van der Meer FJ, Briet E. A method to determine the optimal intensity of oral anticoagulant therapy. Thromb Haemost 1993; 69: 236-239.

35. Origasa H, Goto S, Uchiyama S, Shimada K, Ikeda Y. The Japan Thrombosis Registry for Atrial Fibrillation, Coronary or Cerebrovascular Events (J-TRACE): A nation-wide, prospective large cohort study; the study design. Circ J 2008; 72: 991-997.

36. Hylek EM, Evans-Molina C, Shea C, Henault LE, Regan S. Major hemorrhage and tolerability of warfarin in the first year of therapy among elderly patients with atrial fibrillation. Circulation 2007; 115: $2689-2696$.

37. Pisters R, Lane DA, Nieuwlaat R, de Vos CB, Crijns HJ, Lip GY. A novel user-friendly score (HAS-BLED) to assess 1-year risk of major bleeding in patients with atrial fibrillation: The Euro Heart Survey. Chest 2010; 138: $1093-1100$.

\section{Appendix}

\section{ARISTOTLE-J Study Group}

Members of the Safety and Efficacy of Apixaban for the Prevention of Stroke in Japanese Subjects with Non-Valvular Atrial Fibrillation (ARISTOTLE-J Study) Study Group are as follows:

Steering Committee: Yukito Shinohara (Tachikawa Hospital); Satoshi Ogawa (Mita Hospital).

Clinical Event Committee: Masakatsu Nishikawa (Mie University); Hiroyuki Daida (Juntendo University); Makoto Takagi (Tokyo Saiseikai Central Hospital).

Data and Safety Monitoring Committee: Hideki Origasa (Toyama University); Mitsuru Murata (Keio University Hospital); Takeshi Yamashita (The Cardiovascular Institute); Masahiro Yasaka (National Kyushu Medical Center).

Medical Advisory Committee: Yasuo Ikeda (Waseda University); Shinya Goto (Tokai University).

Pfizer Japan Clinical Core Team: Kazuhiro Kanmuri (Japan Clinical Lead); Michinori Terada and Daisuke Shima (Study Clinicians); Hidekazu Murase (Study Manager), Takashi Moriya (Statistician).

Study Sites Recruiting at Least 1 Patient: The Cardiovascular Institute Hospital; Fukuoka University Hospital; Mito Medical Center; Teine Keijinkai Clinic; St Marianna University; Zentsuji Hospital; Nishi Sapporo National Hospital; Cardiovascular Hospital of Central Japan; Ehime National Hospital; Kyushu University Hospital; Mihara Memorial Hospital; Kyushu Rosai Hospital; Iwakuni Medical Center; Kawasaki Municipal Tama Hospital; Nippon Steel Yawata Memorial Hospital; Kumamoto University Hospital; Ohsaki Heart Clinic; Mie University Hospital; Tosei General Hospital; Ookuma Hospital; Ogaki Municipal Hospital; Nagoya Ekisaikai Hospital; and Keio University Hospital. 